\title{
Design and Implementation of WeChat Public Service Platform for the China Research Center for Agricultural Mechanization Development, CAU
}

\author{
Qing Dong ${ }^{1, a}$, Min-li Yang ${ }^{* 1, b}$ \\ ${ }^{1}$ College of Engineering, China Agricultural University, Beijing 100083, China; *Author for \\ correspondence (Ph.D. Executive Deputy Director, China Research Center for Agricultural \\ Mechanization Development Professor; Phone/Fax: 86-10-62736500) \\ adqjane@126.com, ${ }^{\mathrm{b}}$ qyang@cau.edu.cn
}

\begin{abstract}
In order to speed up the effective integration between the agricultural mechanization and information technology, an information service platform based on WeChat (a mobile social network application in China) is designed for scientific research in this paper. By introducing the characteristics of WeChat public service platform and comparing multiple methods of information diffusion, the 4I model of wireless marketing can solve the conflicting information spreading problem with effectiveness, accurateness and personalization. For illustration, a wireless service platform of the China Research Center for Agricultural Mechanization Development, CAU, based on WeChat is proposed designing and establishing. It includes different function modules, such as client information management, intelligent response service and electronic commerce. Some databases have been designed in the platform, such as agricultural mechanization laws and regulations, statistics databases, research institutions and enterprise information, main crops production modes, agricultural machinery products and subsidies, expert system etc. Practical results show that the wireless network application will be used as the final decision in the information diffusion. It is expected to transfer information with lower costs, improve marketing competitiveness and increase the revenue for the enterprises.
\end{abstract}

Keywords: WeChat public service platform; 4I model of wireless marketing; information diffusion; smart devices, agricultural mechanization

\section{$1 \quad$ Introduction}

The Eighteenth National Congress of the Communist Party of China has put forward to speed up the development of agricultural modernization and effective integration with information technology. Asymmetric information is inevitable in management for modern agriculture industry and is one of the reason block the development successfully. In practice, it is difficult to spread the accurate information of the new equipments and technology and meet the urgent needs of peasants [1,2]. However, the rapid progress in information technology makes it possible to spread the information via the widespread smart phones for agricultural mechanization technology. According 
to International Telecommunication Union (ITU) statistics, by the end of 2014, there are 7 billion mobile-cellular users over the world, with $51.4 \%$ of them in Asia-Pacific region [3]. Fig. 1 shows a strong mobile-cellular user growth since 2005 compared to developed countries and Fig.2 shows a significant increase on share of mobile devices subscriptions by 2000, 2005 and 2014 respectively in developing countries.

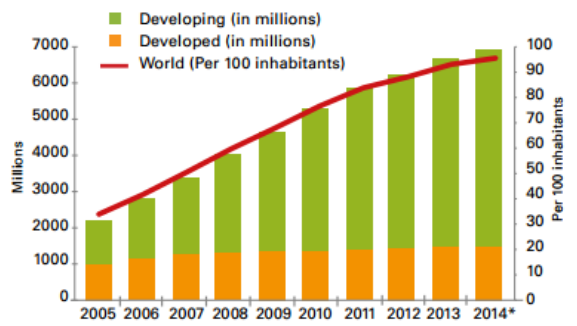

Fig. 1. Mobile-cellular subscriptions, per 100 inhabitants, 2005-2014 (Source: ITU World Telecommunication / ICT Indicators database)
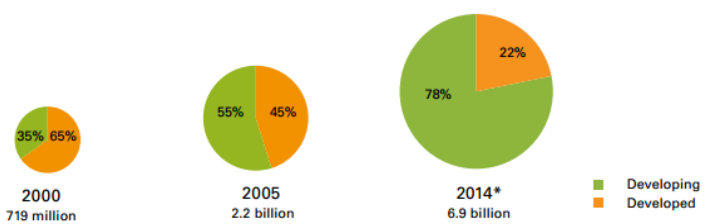

Fig. 2. Share of Mobile-cellular subscriptions, by level of development in 2000, 2005, and 2014 (Source: ITU World Telecommunication / ICT Indicators database)

According to China Internet Network Information Center (CNNIC) statistics, by the end of 2013, there are 0.5 billion mobile user with an annual growth rate of $19.1 \%$ in China [4]. Therefore, a smart phone service platform could be established to spread precise information of agricultural mechanization. One of important of McLuhan's media theories is that the really meaningful and valuable information in media is not the content, but themselves, which represents the nature of communication tools and social transformation in this era [5].

Information diffusion consists of three primary parts: sender, channel and receiver. Actually, the channel has various forms, from traditional oral communication, magazines, newspaper, radio and television [6], to newer and innovated technology computer and wireless network. In recent years, mobile media devices, mobile phones and PDA etc. showed close relationship with agricultural machinery. Particularly, mobile phones play an outstanding performance during Trans-regional operations of farm machines (TROFM) in China. Since 2006, the Ministry of Agriculture (MOA) of the People's Republic of China has signed annual mobile phone information service agreement with Foton Lovol for delivering free weather, traffic, agricultural machinery, even oil supply and operation messages. It has sent message of around 133 million pieces via cell phone to people, who participated in the TROFM and enjoyed an experience of convenient and efficiency from wireless information services [7]. However, this kind of information diffusion model is still a traditional 'one-way communication' [8], which is linear, limited and untimely due to a straight line from 
sender to receiver for informing, persuading or commanding [9]. Even though the users could have dialed to call center for more enquiries, the information is often untimely or inaccurate due to busy line or limited scope of knowledge of operators. This communication model is believed to lack participation, efficient feedback and enough communication in Fig. 3.

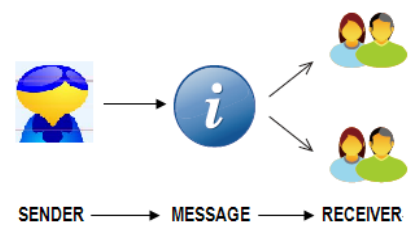

Fig. 3. One-way communication model

Foulger proposed a new ecological model of communication process between information creators, consumers, messages, language and media [10]. The model is demonstrated in Fig. 4, which elaborates Lasswell's five classic communication questions: Who? Say what? In which channel? To whom? What effect? [11]. The answers are: creators for 'Who?' Message for 'says what', languages and media for 'in which channel' that means information transmit with different media in different languages, consumers for 'to whom' receive the messages, and perspectives, attributions, interpretations and others for 'with what effect'.

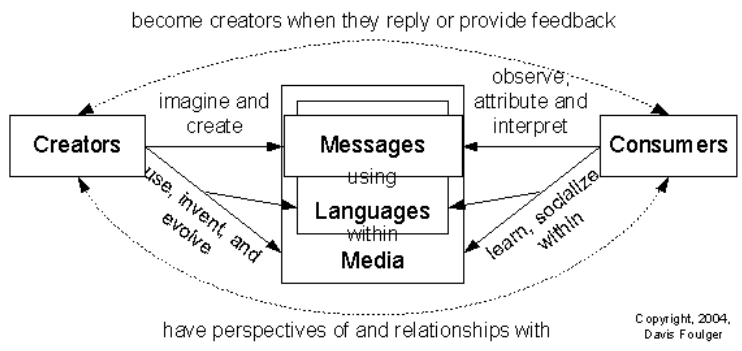

Fig. 4. An ecological model of the communication process

In this paper, although it does not analyze the theory of the five primitives' relationship, which including creators, messages, languages, media and consumers, it proposes a mobile platform based on WeChat application for agricultural mechanization scientific research according to Floulger's theory. Comparing with oneway communication model, it directly forms an interactive network ecological model as shown in Fig. 5.

WeChat, also called 'Weixin' (in Chinese), was created by a Chinese Internet communication conglomerate, named Tencent Company in 2011. It is a free popular mobile instant messaging application, which combines and upgrades the basic functions of SMS (Short Messaging Service) and MMS (Multimedia Messaging Service) in mobile phone [12]. WeChat Public Platform is a social marketing platform that allows government, companies, organizations and others, even sole person to share 
and market products, ideas, views to concerned groups rather than to individual users. The platform has three particular features: 'semacode subscription', 'message pushing' and 'brand communication' [13].

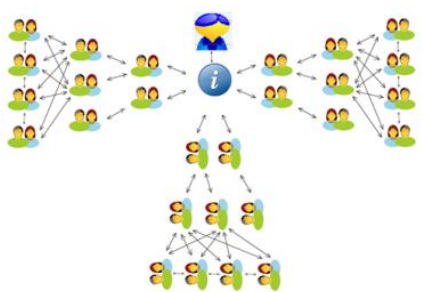

Fig. 5. Interactive network ecological model

In this paper, we propose a public service platform for agricultural mechanization scientific research based on WeChat public platform that consist of different function modules, such as client information management, intelligent response service and electronic commerce. The platform creates client information files through their registration, LBS (Location Based Service) information or when they click on the 'Follow' button. How the intelligent response service works is shown in Fig. 6. It has four solution channels upon any enquiries from users on this platform : (1) Frequently asked questions can be replied by intelligent response on the displays of mobile phones (2) The special problems could be directed to manual service by inputting message or transmitting voice on the platform. (3) The users could search more information by imputing suggestive code to find result. (4) The platform also has an alternative navigation bar as same as the web page via computer. The end user could find more solutions from the navigation information.

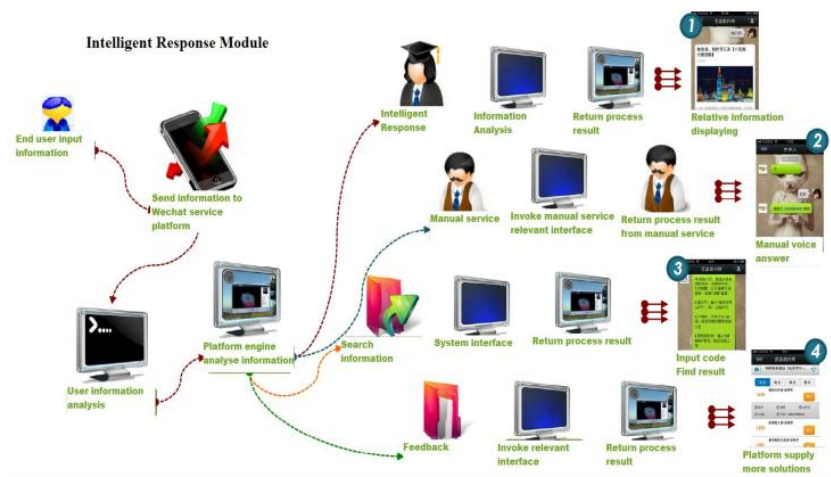

Fig. 6. Intelligent response service 


\section{Design and Implementation of WeChat Public Service Platform for the China Research Center for Agricultural Mechanization Development, CAU}

\subsection{The Start-up Process of WeChat Public Platform}

Hardware, smart devices and WeChat application are required to start the public platform. The platform is equipped with a process that is capable of registering a WeChat official account, which may be either a subscription account or a service account via WeChat service website of an account admin platform. Then the system sends information to smart devices, which have installed in WeChat application. To avoid the spam messages, a subscription account only can send one piece of message per day or four pieces of messages of a service account for a month. The process of start-up WeChat public service platform is presented in Fig. 7.

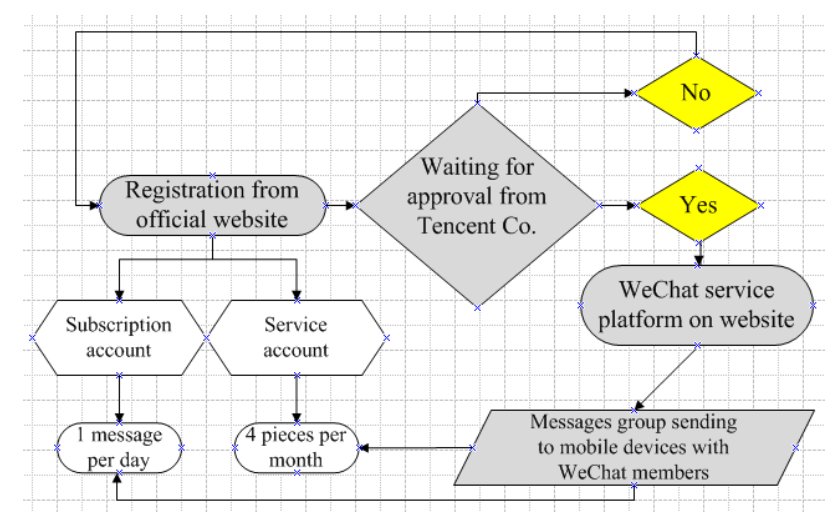

Fig. 7. The process of start-up WeChat public platform

To register on WeChat official website one needs to prepare all relative documents about organizations, then fill in all the blanks or upload the documents after scanning. Options are provided for a service account or a subscription account. The Fig. 8 shows the needed information for registration, including organization type, name, address, contact, business license, business scope, capital, organization code, operator information, certificate of authorization and other supporting documents. 


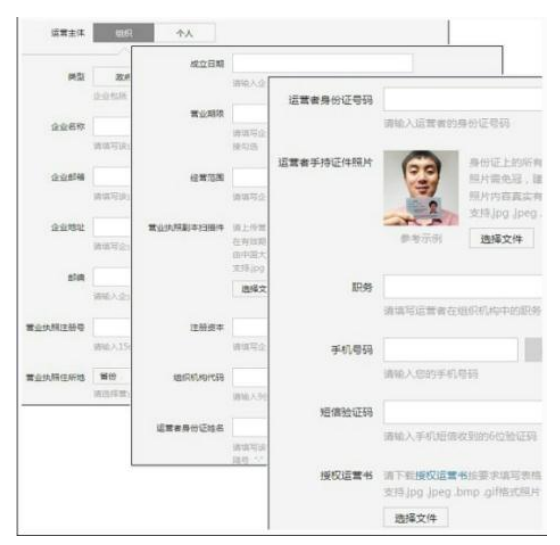

Fig. 8. Registration information

After submitting, the third party of Tencent Company for certification authority would review the documents. If the documents comply with the regulations, the applicant will be able to send grouping messages such as words, voices, pictures, videos and graphics in Chinese or English from the WeChat public service platform to target users, Otherwise, the registration and reviewing have to be performed again.

When searching 'agricultural mechanization' from WeChat public service account, there are 34 items with 34 accounts. By contrast, to search 'Agricultural mechanization' as keywords, it has 200 results with 200 accounts. However, $99 \%$ of them applied subscription account without submitting certification materials, while only few of them owned a service account.

The differences between a subscription account and a service account lie in that an authorized service account has customized menus where item can be set as required, and organization can access the users' basic information, customer interface, voice recognition information, user location information, automatic reply and others. These features are not included in a subscription account.

To start the WeChat public platform for the China Research Center for Agricultural Mechanization Development, CAU, it needs to apply for a service account as well, which take five or seven working days depending on authority schedule. Moreover, each account will be assigned to a unique ID number, like 'gh_e7d52360139a' kind of character string for developers' API.

API (Application Programming Interface) are some pre-defined functions, the purpose is to provide application and a set of accessed routines for developers, which is based on software or hardware without access to original code or detailed internal working mechanism [14]. A URL (Uniform Resource Locator) begins with 'http' and token are needed for the interface in order to represent the right performance of operations. 
2.2 The Design and Implementation of the China Research Center for Agricultural Mechanization Development, CAU Based on WeChat Public Service Platform

The China Research Center for Agricultural Mechanization Development, CAU is the first agricultural mechanization research organization in China established in Department of Engineering, China Agricultural University in Jan. 2011 [15]. The main functions of this center are to realize the combinations of soft science and hard technology, research and solve the major development direction, policy issues of agricultural mechanization and agricultural equipment industry. The goals are to improve theory system of agricultural mechanization with China characteristics, to become a technology communication ligament between agricultural mechanization and agricultural equipment industry by carrying the forum and network, and to provide advisory services for the national decision department [16].

The aims of the design of the WeChat platform for upper research center are to deepen the connection with consumers within agricultural mechanization field, build up database of consumers, scientific industry research, and expert information etc. Therefore, a service account is necessary to provide higher quality services rather than a subscription account. However, the approved service account by registration only is a basic WeChat service platform and more advanced functions will be enabled by connecting with third-party developers' API, such as providing customer service, obtaining users' information that includes open ID, nickname, sex, and location etc. generating a semacode with parameters for further promotion, grouping users and managing multimedia file to upload or download.

The customer service interface is used for handling artificial message by posting a JSON (JavaScript Object Notation) data packet that allows developers to provide more quality services to users. For instance, a kind of JSON data packets for sending two graphics with text messages: 'The Press Conference for $18^{\text {th }}$ World Congress of CIGR was hold' and 'Session VII: Information Systems' are represented as follow.

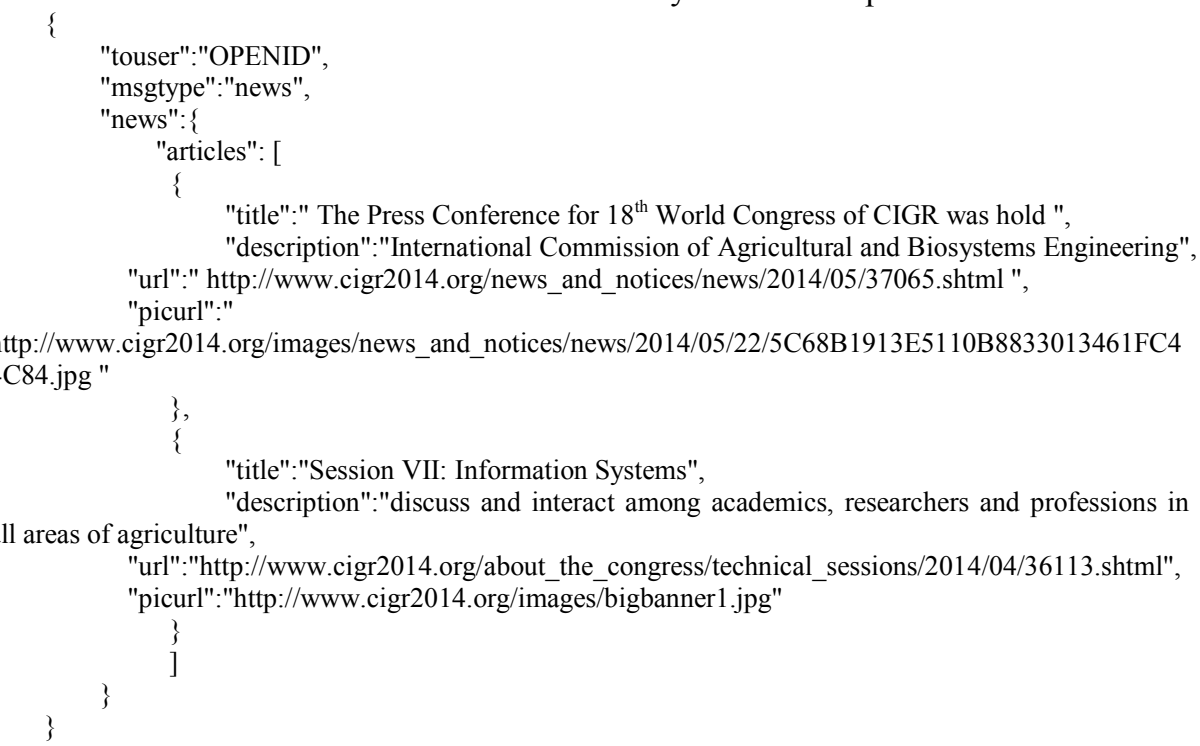


The design sketch of first graphics with textures messages: 'The Press Conference for $18^{\text {th }}$ World Congress of CIGR was hold', for example, is shown in smart phone as Fig. 9 below.

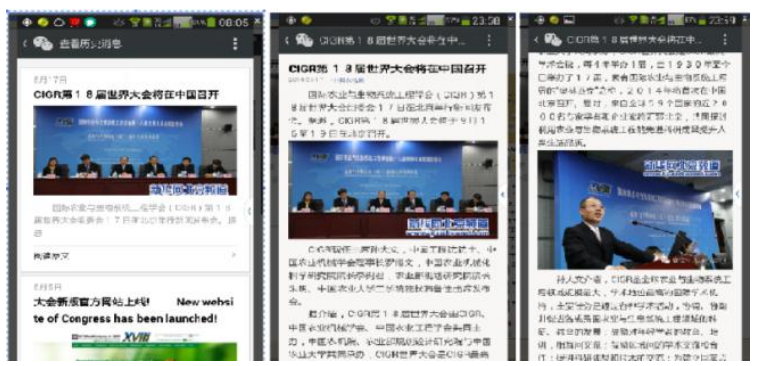

Fig. 9. The graphics with textures messages: 'The Press Conference for $18^{\text {th }}$ World Congress of CIGR was hold' on smart phone via WeChat

All followed users can read the latest news from pushing message is the same as surfing in website. On the other hand, after users followed the account, information senders could build up a customer database from website background management system in this public service platform.

The fundamental part in this platform is the custom menu which is designed to include some databases, such as agricultural mechanization laws and regulations, statistics databases, research institutions and enterprise information, main crops production modes, agricultural machinery products and subsidies, expert system etc.

According to the WeChat regulation of custom menu, it includes three primary navigations with 8 characters (4 Chinese words) mostly and each of navigation contains at most five secondary menus with 14 characters (7 Chinese words) [17]. More characters will be replaced by '...'. Fig. 10 shows the layout of the design structure and Fig. 11 represents the final sketch draft in smart phone.

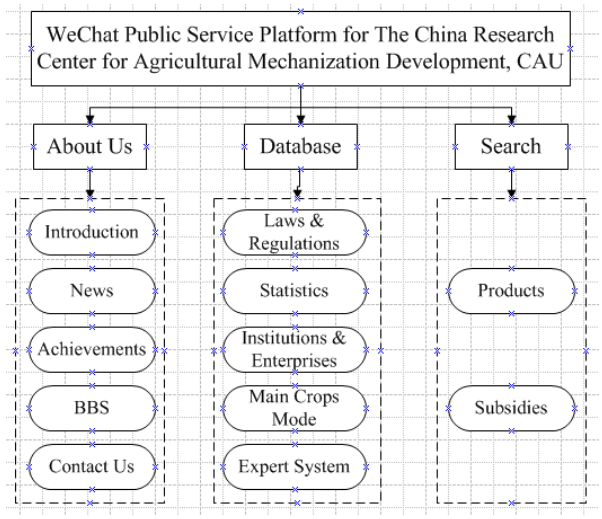

Fig. 10. The structure of WeChat public service platform for the China Research Center for Agricultural Mechanization Development, CAU 


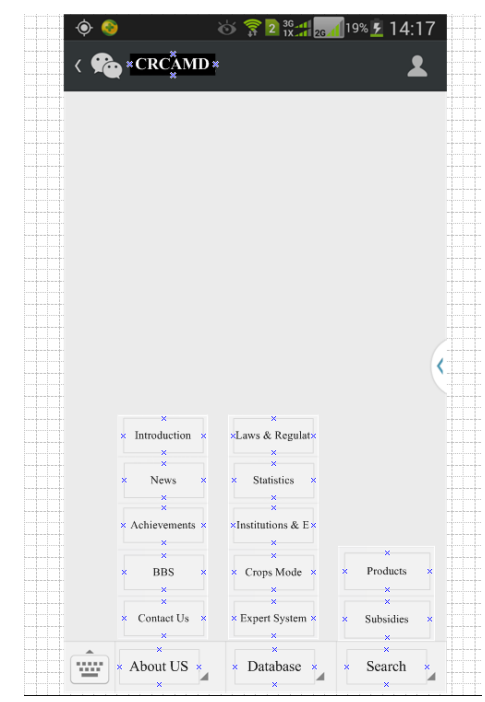

Fig. 11. The final sketch draft of the service platform in smart phone

In Fig. 11, the service account name 'CRCAMD' is the provisional abbreviation name in WeChat public service platform for the China Research Center for Agricultural Mechanization Development, CAU which shows on the top draft. Three primary navigation bars are demonstrated on the bottom line. Moreover, it displays all secondary menu when click each primary navigation bar. After clicking each secondary menu, it will pop up a new html5 page for displaying the final information. If the users need to have a direct conversation with customer service, they should go to the dialog page by clicking the bottom-left keyboard icon. The dialog page shows in Fig. 12, users can send voice, word or picture messages for direct communication.

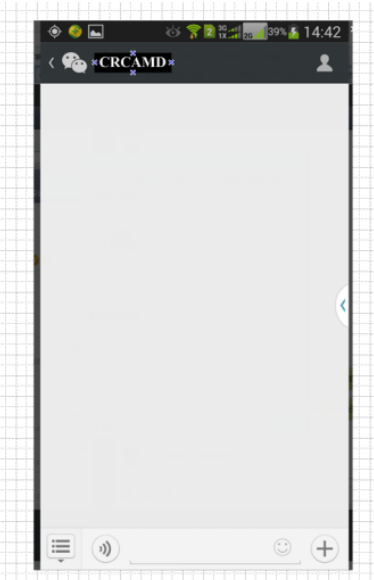

Fig. 12. The dialog page of the service platform in smart phone 


\section{The 4I Model of the WeChat Public Service Platform}

The third generation $(3 \mathrm{G})$ of mobile telecommunication technology brought unlimited business opportunities for marketing. It supports several applications available to $3 \mathrm{G}$ devices users, such as: wireless voice telephone, mobile Internet access, fixed wireless Internet access, video calls and mobile TV technologies [18]. Based on 3G characteristics, marketing strategy has experienced four classical theories from 4P, 4C and 4R to $4 \mathrm{I}$ theory. 4P theory aims to meet the market demands and stands for product, price, promotion and place [19]. 4C theory pursuits the customer's satisfaction as the goal that is included customer, cost, convenience and communication [20]. 4R tries to establish customers' loyalty, consisting of relevance, reaction, relationship and reward [21]. Peter (2003) [22] considers that the companies compete in the market not only through products and services, but also through the business model. Therefore, $3 \mathrm{G}$ and mobile phone media in WeChat era provide an opportunity to discuss the refined marketing relationship through $4 \mathrm{I}$ theory, which is gradually replacing traditional $4 \mathrm{P}$, 4C and 4R theory.

The 4I theory refers to individual identification, instant message, interactive communication and I [23]. The 4I model is showed in the Fig. 13.

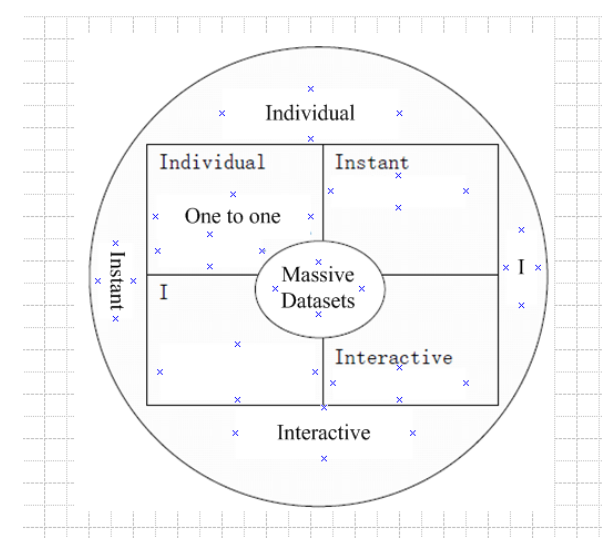

Fig. 13. The $4 \mathrm{I}$ model in wireless marketing

From the 4I model, it shows that the 'interactive' is the core of mobile marketing, 'one to one' is intrinsic character, 'I' and 'instant message' belongs to external performance.

(1) Individual Identification. It subdivides the market according to different individual demands and target groups. The WeChat public service platform can subdivides different groups to do business and create brands in accordance with industry, interests, objective, events etc. In order to achieve these, WeChat has dozens of modular units available for doing various tasks, such as micro official website, micro research, micro mart, micro payment, micro membership, and micro community and so on.

(2) Instant Message. It is the distinctive function in WeChat. Each sender can respond in time to meet customers' demands and desires via the instant customer 
service. Furthermore, it creates possibilities for deep refine market by dynamic feedback and interactive tracking actions of wireless mobile phone.

(3) Interactive Communication. It emphasizes the customer participation in the marketing. This WeChat public service platform can greatly enhance customer loyalty and satisfaction when they have good communication and timely response experience. For instance, the micro membership improves the user usage and increases the product viscosity.

(4) I. It expresses the personality characteristic and refers to individual needs, exchanges and other personality communications [24].

(5) In this matrix column, it presents a three-dimensional circulation of propagation. Enterprises attract and impact potential customers through WeChat service account, then use html5 to load the information flow. Html5 has more characteristics than html, such as geographical location and local storage. After transforming information flows to download application (App), enterprises manage information and user database through the platform. Among seamless communication of WeChat service account with html5, App and WeChat public service platform, it forms upper referred matrix and own brand media matrix in order to promote the whole media operation.

\section{Conclusions}

This paper explores the present developing level of information diffusion service in China, particularly the application of social networking service WeChat public service platform which created by Chinese Internet communication company "Tencent". Globally, WeChat public service platform with dozens of advanced modular units and special characteristics is gaining popularity. Governments, organizations, firms even persons can employ this platform to market themselves. Compared with the traditional one-way media communication, the platform provides more convenient, participative and interactive dialogue functions for the general public. Similar to agricultural mechanization companies and organizations, they have their own customers and approaches to promote themselves. As a result of the increasing utilization of WeChat application within smart phone, the public service platform is a new promotional instrument for information diffusion. It contributes to the publicity of product brands, because of high forwarding and transmission rates.

This paper also illustrates the establishment and implement of the WeChat public service platform of the China Research Center for Agricultural Mechanization Development, CAU. It elaborates the detailed processes including service account application, connecting with third-party developers' API for advanced promotion and providing higher quality services in order to enhance the satisfaction and identification of customers.

At the end of this paper, it cites a three-dimensional circulation of propagation matrix from 4I model for analyzing how the WeChat public service platform can satisfy the refined marketing, diversified requirements and personalized service.

Practical results show that the wireless network application will be used as the final decision in information diffusion. It is expected to transfer information in lower costs, improve marketing competitiveness and increase the revenue for the enterprises. 


\section{Acknowledgment}

A fund for this research was provided by the Beijing Lianhui Digital Technology Limited Company. Meanwhile, the authors thank all senior experts, professors and staffs, who are working for the China Research Center for Agricultural Mechanization Development, CAU for their valuable and constructive comments.

\section{References}

1. Zhang Li, Analysis on the existing problems in agricultural mechanization extension and improvement strategy [J], Business. 2013 (4):253.

2. Wang Mingjian, The ideas and countermeasures of agricultural mechanization extension under the new situation [J], Modern Agricultural Equipments, 2012 (7): 36-38.

3. ITU., The world in 2014: facts and figures [EB/OL], http://www.itu.int/en/ITUD/Statistics/Documents/facts/ICTFactsFigures2014-e.pdf, retrived on 2014-04-23

4. CNNIC., Statistical Report on Internet Development in China [R], 2014.

5. McLuhan, M., Marshall McLuhan's Theory of Communication [M]. Global Media JournalCanadian Edition, 2008.

6. Levinson, P. New New Media [M]. Shanghai: Fudan University Press, 2011.

7. Bai Lu, The Information Service Continue to Upgrade in this Summer, China Agricultural Mechanization Herald [EB/OL],
[ http://www.amic.agri.gov.cn/nxtwebfreamwork/detail.jsp?articleId=ff808081377ca6b801377 cd96b8402b9, retrived on 2014-05-21.

8. Scott, A. Le Gall Francois, Alexander R, et al. The One-Way Communication Complexity of Subgroup Membership [J], Chicago Journal of Theoretical Computer Science, 2011(6): 116.

9. Shannon, C. E. and Weaver, W. The mathematical theory of communication [M]. Illinois: University of Illinois Press, 1949.

10. Foulger, D. An Ecological Model of the Communication Process [EB/OL], http://davis.foulger.info/papers/ecologicalModelOfCommunication.htm, retrived on 2014-0503.

11. Lasswell, H. The structure and function of communication in society [M], New York: Institute for Religious and Social Studies, 1948.

12. Sunny, Y. Weixin-Tencent's Bringing the Mobile IM Revolution to the Mainstream [EB/OL], http://techrice.com/2011/09/21/weixin-tencents-bringing-the-mobile-im-revolutionto-the-mainstream/, retrived on 2014-05-11.

13. China TMT Daily, Weixin Public Platform [R], Deutsche Bank Markets Research, 2012.

14. Wikipedia, Application programming interface [EB/OL], http://en.wikipedia.org/wiki/Api, retrived on 2014-04-25.

15. The Formal Establishment of The Development and Research Center of China Agricultural Mechanization
[EB/OL], http://www.camn.agri.gov.cn/Html/2011_01_17/2_1887_2011_01_17_16052.html, retrived on 2014-03-02.

16. Baidu Encyclopedia, The Development and Research Center of China Agricultural Mechanization $[\mathrm{EB} / \mathrm{OL}]$, http://baike.baidu.com/link?url=EnIcfpG78MACg4oK_NeVMZtVFWamMk7XPn6XPzdiVw IvPakv8hSHTwLwIBH4VIozjj1elk0Q1PddKITH05t39q, retrived on 2014-03-02 
17. WeChat,

Creator's

File

[EB/OL],

http://mp.weixin.qq.com/wiki/index.php?title=19S2qNLlssu1pbS0vai907/a, retrived on 2014$05-12$

18. Wikipedia, 3G [EB/OL], http://en.wikipedia.org/wiki/3g, retrived on 2014-06-20.

19. William, D., Perreault, J., Joseph, P.C. et al., Basic Marketing (18th Revised edition) [M], McGraw Hill Higher Education, 2010.

20. Lauterborn, R. New Marketing Litany: Four Ps Passé: C-Words Take Over [J], Advertising Age, 1990, 41 (61): 26.

21. Schultz, D. E., Tannenbaum, S. I., and Lauterborn, R. F. Integrated Marketing Communications [M], McGraw-Hill, 1993.

22. Drucker, P. F., Peter Drucker on the Profession of Management - A Harvard Business Review Book [M], Harvard Business Review Press, 2003.

23. Zhu Haisong, Wireless Marketing [M]: The Adaptability of the Fifth Media Interaction, Guangdong Economic, 2006.

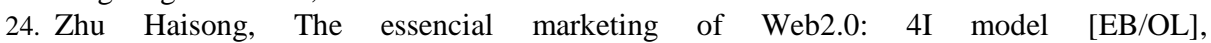
http://column.iresearch.cn/u/zhuhaisong/3887.shtml, retrived on 2014-05-22 